\title{
COMPARATIVE CLINICAL EVALUATION OF TACROLIMUS AND CYCLOSPORINE EYE DROPS FOR THE TREATMENT OF CANINE KERATOCONJUNCTIVITIS SICCA
}

\author{
Krzysztof RADZIEJEWSKI $^{1}$ and Ireneusz BALICKI ${ }^{2 *}$ \\ ${ }^{1}$ Veterinary Clinic 'Radwet', Słupsk, Poland; ${ }^{2}$ Department and Clinic of Animal Surgery, \\ Faculty of Veterinary Medicine, University of Life Sciences in Lublin, \\ 13 Akademicka Street, 20-950 Lublin, Poland
}

(Received 27 July 2015; accepted 4 May 2016)

The aim of this study was to evaluate the efficacy of tacrolimus eye drops in alleviating the clinical symptoms of canine keratoconjunctivitis sicca (KCS) and to compare this efficacy with that of cyclosporine. The clinical study was conducted on 40 dogs diagnosed with idiopathic KCS. The dogs were divided into two groups of 20 animals each. In Group I, $0.75 \%$ cyclosporine eye drops were administered three times a day, while in Group II $0.02 \%$ tacrolimus eye drops were given twice daily. In addition, each group was subdivided into three subgroups based on the results of Schirmer tear test I (STT I). Clinical and ophthalmologic examinations were performed prior to the treatment as well as after one and two months of therapy. The application of both tacrolimus and cyclosporine resulted in a significant reduction of neovascularisation after the first and second month of treatment $(\mathrm{P}<0.05, \mathrm{P}<0.001)$; however, in moderate and advanced stages, the observed efficacy of tacrolimus was higher. Across all patients, a significant increase in STT I values was observed after both the first and second month of treatment with tacrolimus $(\mathrm{P}<0.01)$, as well as after two months of treatment with cyclosporine $(\mathrm{P}<0.05)$. In both groups, some patients were observed to exhibit inhibited development of pigmentation, but an analysis of particular clinical cases and statistical data revealed no statistically significant discrepancies in the course of the study. In cases of advanced canine KCS, the efficacy of tacrolimus may be higher than that of cyclosporine.

Key words: Keratoconjunctivitis sicca, dog, cyclosporine, tacrolimus

Keratoconjunctivitis sicca (KCS) is an eye disease involving a disorder in tear production and/or incorrect composition of the tear film. Untreated or incorrectly treated KCS may lead to eyesight impairment, even blindness (Aguirre et al., 1971; Kaswan et al., 1985; Bartnett, 1997; Balicki et al., 2008; Bonagura and Twedt, 2009). In most clinical cases, immune-mediated KCS is diagnosed, involving infiltration by mononuclear cells and atrophy of the glandular tissue of

*Corresponding author; E-mail: balicki.ireneusz@gmail.com; Phone: 0048 (603) 066-376; Fax: 0048 (8181) 524-3808 
lacrimal glands, which results in a decrease or complete cessation of secretory activity (Kaswan et al., 1984; Whitley et al., 1991).

The first noticeable symptoms include conjunctival redness, abnormal contraction of the eyelid (blepharospasm), and the presence of exudate in the conjunctival sac (Miller, 2008).

One of the typical KCS symptoms is the presence in the conjunctival sac of a mucous, mucopurulent or purulent, often sticky exudate. Dogs suffering from KCS tend to suffer from disorders of corneal transparency. The improperly moistened cornea loses its shininess and becomes opaque. As a result of the inflammation the cornea becomes swollen, which further reduces its transparency, and vascular ingrowth occurs. This is often accompanied by photophobia. Another characteristic symptom of KCS is corneal pigmentation (Kaswan et al., 1995). As the disease progresses, the swelling, vascular ingrowth and pigmentation spread to a growing area of the cornea, leading to eyesight deterioration, and in extreme cases to blindness (Kaswan et al., 1995). In the absence of a tear film, corneal epithelial defects occur, followed by ulceration. Ulcers are typically located in the centre of the cornea (Kaswan et al., 1995; Miller, 2008).

The diagnosis of KCS is based on data collected from interviews, recognition of clinical symptoms, and results of the Schirmer tear test (STT) (Trbolova, 2005; Miller, 2008). STT results below $15 \mathrm{~mm} / \mathrm{min}$ are considered inadequate and an indication of KCS. Three stages of KCS advancement can be identified based on the STT value (Giuliano and Moore, 2007): early or subclinical stage of KCS - STT 11-14 mm/min; moderate or mild stage of KCS -STT 6-10 $\mathrm{mm} / \mathrm{min}$; severe stage of KCS - STT 0-5 mm/min.

The treatment of KCS is primarily based on cyclosporine (CsA), applied in the form of drops diluted in castor oil, corn oil, rape oil, or olive oil in concentrations ranging from $0.5 \%$ to $2 \%$, as well as ready-made $0.2 \%$ ophthalmologic ointment (Optimune, MSD Animal Health) (Kaswan et al., 1989; Morgan and Abrams, 1991). One of the first studies on the use of cyclosporine in KCS treatment was published by Kaswan et al. (1989), who attempted to treat KCS with $2 \%$ cyclosporine in corn oil. In the course of the therapy, the STT results improved by $5 \mathrm{~mm} / \mathrm{min}$ or more in $59 \%$ of the animals. After several months of treatment, corneal neovascularisation and pigmentation were reduced. Herrera and Lightowler (1994) conducted a study in which patients with STT results between 6 and $10 \mathrm{~mm}$ were treated with $2 \%$ cyclosporine, and were able to report return to the normal STT range in $93.6 \%$ of the cases. They also observed return to the original STT value in $80.5 \%$ of patient whose STT value at the beginning of the treatments was between 2 and $6 \mathrm{~mm}$. However, patients whose STT value was not increased still showed an improvement in terms of the clinical condition of the cornea and conjunctiva. Another study confirmed the high efficacy of a $1 \%$ solution of cyclosporine in olive oil administered to patients suffering from KCS once every twelve hours. The therapy was conducted on 22 dogs for a pe- 
riod of 4 weeks. An increase in STT results of $5 \mathrm{~mm}$ or more was observed in $86.4 \%$ of the patients, while improvement in terms of clinical symptoms was reported in $81.8 \%$ of the dogs (Olivero et al., 1991). The treatment of KCS also included the use of a newly developed aqueous calcineurin inhibitor, SCY-641. It is a semi-synthetic derivative of cyclosporine which was used in the course of KCS treatment in the form of $0.03 \%$ eye drops. The use of SCY-641 in sick dogs resulted in significantly higher STT than that observed in placebo-treated dogs (Gilger et al., 2013).

Another compound with characteristics and activity mechanisms similar to those of cyclosporine is tacrolimus. It is a macrolide antibiotic isolated from Streptomyces tsukubaensis. Its immunomodulatory effect is similar to that of CsA (Kino et al., 1987; Kilmartin et al., 1998). Berdoulay et al. (2005) used a $0.02 \%$ water solution of tacrolimus, administered twice daily, in the treatment of 105 dogs suffering from KCS. Animals qualified for the study were dogs that had not undergone prior stimulation of tear secretion, dogs successfully treated with cyclosporine, as well as animals for whom cyclosporine treatment proved ineffective. An increase in STT results by $5 \mathrm{~mm} / \mathrm{min}$ or more was reported in $85 \%$ of the previously untreated animals and in $51 \%$ of animals previously unsuccessfully treated with cyclosporine. In all dogs with a reported good response to cyclosporine, the treatment change to tacrolimus was successful and rendered the same therapeutic effect. Apart from the change in the STT value, an improvement in terms of clinical symptoms was also observed. Despite failing to evaluate the degree of corneal pigmentation and vascularisation, the authors reported a significant clinical improvement. No hypersensitivity to tacrolimus was observed, which suggests that this treatment can be administered to animals with a low tolerance to cyclosporine.

The aim of this study was to evaluate the efficacy of KCS treatment with $0.75 \%$ cyclosporine eye drops in comparison to treatment with $0.02 \%$ tacrolimus eye drops administered for a period of two months.

\section{Materials and methods}

Animals qualified for the study included 40 dogs of various breeds including mixed-breed dogs, 21 females and 19 males, aged between 1 and 13 years, diagnosed with idiopathic KCS and previously untreated for the disease (Tables 1 and 2). The patients underwent detailed ophthalmic examinations using a slit lamp as well as indirect and direct ophthalmoscopy. Schirmer tear test I values were determined with the use of standard strips (Schering Plough Animal Health). All dog owners were comprehensively interviewed. The dogs were also subjected to thorough clinical examination in order to exclude other diseases. In all dogs, complete blood cell count tests were conducted using a URIT-2900 Vet 
apparatus (Guilin Botest Medical Electronic Co. Ltd.). Serum biochemical profiles were performed to determine the activities of alanine transaminase, alkaline phosphatase and aspartate transaminase, as well as the levels of urea, complete bilirubin, creatinine and glucose using a Rayto RT-1904 VET apparatus (Rayto Electronics Inc.). The dogs showed no clinical symptoms other than ophthalmological signs, as confirmed by the haematological and biochemical tests performed. Animals diagnosed with hypothyroidism were excluded from the study.

Table 1

Breed, sex and age of dogs in Group I

\begin{tabular}{|c|c|c|c|}
\hline $\begin{array}{l}\text { Patient } \\
\text { number }\end{array}$ & Breed & Sex & $\begin{array}{c}\text { Age } \\
\text { (years) }\end{array}$ \\
\hline \multicolumn{4}{|c|}{ Subgroup I } \\
\hline 1 & Poodle & 우 & 12 \\
\hline 2 & Pug & $\hat{\sigma}$ & 5 \\
\hline 3 & Poodle & $\hat{\sigma}$ & 9 \\
\hline 4 & Yorkshire Terrier & q & 12 \\
\hline 5 & Yorkshire Terrier & $\hat{\sigma}$ & 1 \\
\hline 6 & Chow Chow & 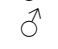 & 6 \\
\hline \multicolumn{4}{|c|}{ Subgroup II } \\
\hline 1 & Yorkshire Terrier & q & 3.5 \\
\hline 2 & French Bulldog & $\hat{\sigma}$ & 5 \\
\hline 3 & Shih-Tzu & $\delta$ & 2 \\
\hline 4 & West Highland White Terrier & q & 6 \\
\hline 5 & Pekingese & $\hat{\sigma}$ & 8 \\
\hline 6 & Yorkshire Terrier & $\hat{\sigma}$ & 4 \\
\hline 7 & Shih-Tzu & q & 2 \\
\hline \multicolumn{4}{|c|}{ Subgroup III } \\
\hline 1 & Shih-Tzu & q & 1 \\
\hline 2 & Poodle & $\hat{\sigma}$ & 12 \\
\hline 3 & Siberian Husky & $\delta$ & 4 \\
\hline 4 & Labrador & $\hat{\sigma}$ & 5 \\
\hline 5 & Miniature Schnauzer & $\delta$ & 6 \\
\hline 6 & Yorkshire Terrier & 우 & 1.5 \\
\hline 7 & Poodle & q & 10 \\
\hline
\end{tabular}

The dogs were divided into two study groups based on the type of treatment received. In Group I, 20 animals were treated with cyclosporine $(0.75 \%$ eye drops) administered three times a day.

In Group II, 20 animals were treated with tacrolimus ( $0.02 \%$ eye drops) administered twice a day.

Furthermore, each group was subdivided into three subgroups on the basis of the STT I results: subgroup I (6 dogs) - STT I values between 0 and 5, sub- 
group II (7 dogs) - STT I values between 6 and 10, and subgroup III (7 dogs) STT I values between 11 and 14. In two Group I animals and three Group II animals the disease was unilateral.

Table 2

Breed, sex and age of patients in Group II

\begin{tabular}{|c|c|c|c|}
\hline $\begin{array}{l}\text { Patient } \\
\text { number }\end{array}$ & Breed & Sex & $\begin{array}{c}\text { Age } \\
\text { (years) }\end{array}$ \\
\hline \multicolumn{4}{|c|}{ Subgroup I } \\
\hline 1 & Chow Chow & $\hat{0}$ & 3.5 \\
\hline 2 & Cocker Spaniel & 우 & 4 \\
\hline 3 & Pekingese & 우 & 9 \\
\hline 4 & Miniature Schnauzer & $\hat{o}$ & 8 \\
\hline 5 & Yorkshire Terrier & q & 4 \\
\hline 6 & Pug & $\hat{\sigma}$ & 7 \\
\hline \multicolumn{4}{|c|}{ Subgroup II } \\
\hline 1 & Shih-Tzu & 우 & 2 \\
\hline 2 & Chow Chow & $\hat{0}$ & 1 \\
\hline 3 & Golden Retriever & 우 & 7 \\
\hline 4 & Shih-Tzu & 우 & 2 \\
\hline 5 & Yorkshire Terrier & $\hat{o}$ & 3 \\
\hline 6 & Mix breed & 우 & 13 \\
\hline 7 & Poodle & $\sigma^{\lambda}$ & 12 \\
\hline \multicolumn{4}{|c|}{ Subgroup III } \\
\hline 1 & Cocker Spaniel & o & 1 \\
\hline 2 & Poodle & $\widehat{\delta}$ & 5 \\
\hline 3 & Chow Chow & $\hat{\sigma}$ & 1 \\
\hline 4 & Yorkshire Terrier & $\hat{\sigma}$ & 3 \\
\hline 5 & Mix breed & 우 & 7 \\
\hline 6 & Labrador & o & 11 \\
\hline 7 & Poodle & 字 & 10 \\
\hline
\end{tabular}

Where purulent exudate was observed in the conjunctival sac, patients received $0.3 \%$ ofloxacin in the form of eye drops (Floxal, Dr Mann Pharma) administered four times daily for a period of two weeks. If the purulent exudate persisted, the patients received a 2 -week treatment with $0.3 \%$ tobramycin drops (Tobrosopt, Polfa S.A) administered four times daily. In cases of corneal ulceration, dexpanthenol (Corneregel, Dr Mann Pharma) was additionally administered three times a day.

Clinical signs were evaluated as follows: conjunctival hyperaemia (score 0 : no conjunctival hyperaemia, 1 : mild hyperaemia, 2 : moderate hyperaemia, 3 : significant hyperaemia), ocular discharge (score 0: no ocular discharge, 1: small amount of mucous exudate in the conjunctival sac; 2 : mucopurulent exudate pre- 
sent in the medial canthus, 3: purulent exudate present along the lower eyelid margin, 4: purulent exudate present on the eyelids and in the vicinity of the eye socket), area of corneal pigmentation (score 0: no corneal pigmentation, 1: pigmentation over less than $25 \%$ of the cornea, 2: pigmentation over $25-50 \%$ of the cornea, 3: pigmentation over $50-75 \%$ of the cornea, 4 : pigmentation over $>75 \%$ of the cornea), corneal transparency (score 0 : full transparency, 1: reduced transparency - iris poorly visible, 2: lack of transparency), vascular ingrowth in particular corneal quadrants (score 0: no corneal vessels, 1: vascular ingrowth in one corneal quadrant, 2: vascular ingrowth in two corneal quadrants, 3: vascular ingrowth in three corneal quadrants, 4: vascular ingrowth in four corneal quadrants), corneal defect (score 0: no corneal defect, 1: corneal defect stained by fluorescein).

Ophthalmic examinations were conducted prior to the treatment, as well as after one and two months of therapy. The degree of corneal neovascularisation and pigmentation was assessed on the basis of photographs.

The study utilised two types of statistical data: numerical (quantitative) and qualitative. The results obtained from Schirmer tear test I were checked for normal distribution on a Gaussian curve. For this purpose, the Shapiro-Wilk test was applied, which did not confirm normal distribution. For that reason, results were interpreted by calculating the median, maximum and minimum values. In the case of qualitative data pertaining to vascular ingrowth and pigmentation, the results were quantified by considering the number of quadrants affected by neovascularisation and the number reflecting the degree of pigmentation. In assessing the degree of neovascularisation and pigmentation, Pearson's non-parametric $\chi^{2}$ (chi-squared) independence test was used, which is suitable for analyses of qualitative data. Statistical analyses were conducted for groups considered as a whole, without accounting for group subdivisions.

\section{Results}

Data obtained from the animals' owners revealed that in four dogs cyclosporine eye drops caused irritation as indicated by the animals' tendency to rub the area of the eye socket shortly after administration. The effect ceased after several minutes. The owners also reported that the dogs which initially showed side effects would gradually become used to the eye drops over a 2- to 3-week period of therapy, and the irritation would eventually cease or become less intensive.

In both groups, the observed regression of clinical symptoms was gradual, with the individual response to treatment varying between particular animals. In the case of two conjunctival sacs in Group I and 4 in Group II, the degree of conjunctival redness did not change over the entire course of treatment. Moreover, in one patient treated with tacrolimus, the degree of conjunctival redness decreased 
after the first month but returned to the original level at the end of the 2-month therapy. In other patients from both groups the administered treatments resulted in a reduction of conjunctival redness.

Before treatment in Group I, 3rd degree purulent exudate was observed in 17 conjunctival sacs, 4th degree in 10, 2nd degree in 9, and 1st degree in 2 . In Group II, before treatment, 3rd degree purulent exudate was present in 19 conjunctival sacs, 4th degree in 9, and 2nd degree in 9. The administered treatment resulted in a reduction of conjunctival sac exudation. After one month of tacrolimus treatment, exudation in 33 of 37 conjunctival sacs was reduced, and the effect extended to all conjunctival sacs after the second month of therapy. In the group treated with cyclosporine, improvement in terms of exudation was observed in 30 out of 38 affected conjunctival sacs after the first month, and 34 after 2 months of treatment. At the end of the two-month treatment no patient in either group was diagnosed with 4th degree conjunctival sac purulent exudation. Third degree purulent exudation persisted in 4 conjunctival sacs in Group I and 2 in Group II. In the remaining patients, 1 st and 2nd degree mucous exudation was observed. In 3 conjunctival sacs in Group I and 5 in Group II no exudation was present.

The results of Schirmer tear test I during the treatment of KCS in Groups I and II were presented in Tables 3 and 4. A statistically significant increase in the STT I value was observed after two months of treatment with cyclosporine and in both the first and second month of treatment with tacrolimus (Table 5). An increase in STT I values of $5 \mathrm{~mm} / \mathrm{min}$ or more was observed in 11 conjunctival sacs after one month of treatment and in 21 after two months of treatment in Group II, compared to 6 conjunctival sacs after one month and 15 after two months of treatment in Group I. In subgroup I of Group I, after one month of treatment an STT I value increase of $5 \mathrm{~mm} / \mathrm{min}$ or more was observed in 2 conjunctival sacs and after two months in $5 \mathrm{sacs}$, compared to a respective $5 \mathrm{~mm} / \mathrm{min}$ increase in 4 conjunctival sacs after one month and 7 after two months of treatment in Group II. In subgroup II of Group I, an increase in STT I values of $5 \mathrm{~mm} / \mathrm{min}$ or more was observed in 2 conjunctival sacs after one month and 6 after two months of treatment, compared to a respective STT I increase by $5 \mathrm{~mm} / \mathrm{min}$ or more in 6 conjunctival sacs after one month and 10 after two months recorded in Group II. A STT I increase of $5 \mathrm{~mm}$ or more in respective subgroups III was observed in 2 conjunctival sacs in Group I and 1 in Group II after the first month of treatment, and in 4 conjunctival sacs in either group after the second month of therapy. In one Group I case no STT I increase was observed throughout the treatment. Moreover, in 2 cases of Group I and 2 cases of Group II, the STT I values decreased compared to the values recorded prior to the treatment. In yet another patient in the group receiving cyclosporine, the STT I value remained at 0 throughout the therapy. 
Table 3

Results of Schirmer tear test I during the treatment of keratoconjunctivitis sicca (KCS) in Group I

\begin{tabular}{|c|c|c|c|c|c|c|}
\hline \multirow{3}{*}{$\begin{array}{l}\text { Patient } \\
\text { number }\end{array}$} & \multicolumn{6}{|c|}{ Result of Schirmer tear test I (mm) } \\
\hline & \multicolumn{2}{|c|}{ Before treatment } & \multicolumn{2}{|c|}{ After 1 month of treatment } & \multicolumn{2}{|c|}{ After 2 months of treatment } \\
\hline & Right eye & Left eye & Right eye & Left eye & Right eye & Left eye \\
\hline \multicolumn{7}{|c|}{ Subgroup I } \\
\hline 1 & 5 & 4 & 8 & 7 & 9 & 7 \\
\hline 2 & 2 & 5 & 5 & 10 & 6 & 11 \\
\hline 3 & 4 & 4 & 6 & 8 & 9 & 10 \\
\hline 4 & 5 & 4 & 4 & 3 & 2 & 1 \\
\hline 5 & - & 0 & - & 0 & - & 0 \\
\hline 6 & 5 & 5 & 9 & 11 & 12 & 14 \\
\hline \multicolumn{7}{|c|}{ Subgroup II } \\
\hline 1 & 9 & 10 & 14 & 14 & 14 & 16 \\
\hline 2 & 8 & 9 & 12 & 13 & 14 & 14 \\
\hline 3 & 7 & 6 & 9 & 10 & 11 & 10 \\
\hline 4 & 6 & 10 & 8 & 11 & 9 & 12 \\
\hline 5 & 9 & 8 & 10 & 11 & 11 & 10 \\
\hline 6 & 10 & 9 & 13 & 13 & 14 & 13 \\
\hline 7 & 6 & 9 & 12 & 13 & 14 & 14 \\
\hline \multicolumn{7}{|c|}{ Subgroup III } \\
\hline 1 & 11 & 13 & 16 & 17 & 16 & 15 \\
\hline 2 & 12 & 11 & 9 & 10 & 9 & 8 \\
\hline 3 & 12 & 11 & 14 & 11 & 15 & 12 \\
\hline 4 & 14 & 13 & 14 & 14 & 15 & 14 \\
\hline 5 & 11 & 12 & 15 & 14 & 16 & 14 \\
\hline 6 & - & 11 & - & 14 & - & 15 \\
\hline 7 & 12 & 13 & 17 & 16 & 19 & 20 \\
\hline
\end{tabular}

After one month of treatment, an increase in transparency was observed in 13 of 31 corneas in Group I and 11 of 27 corneas in Group II. After the subsequent month, an increase in transparency was recorded in another 4 corneas in Group I and 9 in Group II. After two months of treatment, an improvement in terms of transparency was observed in a total of 17 of 31 corneas in Group I and 20 of 27 corneas in Group II.

The use of tacrolimus or cyclosporine in the treatment of KCS resulted in a statistically significant decrease in vascular ingrowth after both the first and second month of therapy; however, tacrolimus therapy decreased corneal neovascularisation in a higher number of quadrants (Tables 6 and 7). An analysis of vascular ingrowth revealed a higher efficacy of tacrolimus in subgroup I, where the symptoms were the most intensive, with a decrease in corneal neovasculari- 
sation observed in 6 corneas after one month and 7 corneas after two months of treatment, compared to subgroup I of Group I where the same was observed in 4 corneas after one month and 5 corneas after two months of therapy. In subgroup II, the discrepancy between the particular preparations in terms of efficacy in countering corneal neovascularisation was even more apparent. Of 11 corneas affected by vascular ingrowth, improvement was observed in 3 corneas after one month and 9 corneas after two months of treatment with cyclosporine. By comparison, in the group receiving tacrolimus, improvement was observed in 8 out of 10 corneas after the first month, and in all affected corneas after two months of therapy. In subgroup III, after two months of treatment with either tacrolimus or cyclosporine, reduced corneal neovascularisation was observed in all patients from both groups.

Table 4

Results of Schirmer tear test I during the treatment of keratoconjunctivitis sicca (KCS) in Group II

\begin{tabular}{|c|c|c|c|c|c|c|}
\hline \multirow{3}{*}{$\begin{array}{l}\text { Patient } \\
\text { number }\end{array}$} & \multicolumn{6}{|c|}{ Result of Schirmer tear test I (mm) } \\
\hline & \multicolumn{2}{|c|}{ Before treatment } & \multicolumn{2}{|c|}{ After 1 month of treatment } & \multicolumn{2}{|c|}{ After 2 months of treatment } \\
\hline & Right eye & Left eye & Right eye & Left eye & Right eye & Left eye \\
\hline \multicolumn{7}{|c|}{ Subgroup I } \\
\hline 1 & 3 & 5 & 14 & 13 & 13 & 13 \\
\hline 2 & 4 & 3 & 8 & 9 & 9 & 10 \\
\hline 3 & 2 & 2 & 1 & 1 & 1 & 0 \\
\hline 4 & 4 & 5 & 4 & 3 & 2 & 3 \\
\hline 5 & 0 & - & 4 & - & 5 & - \\
\hline 6 & 5 & 4 & 9 & 9 & 11 & 10 \\
\hline \multicolumn{7}{|c|}{ Subgroup II } \\
\hline 1 & 10 & 7 & 17 & 15 & 18 & 16 \\
\hline 2 & 8 & - & 12 & - & 15 & - \\
\hline 3 & 6 & 8 & 11 & 12 & 13 & 14 \\
\hline 4 & 6 & 6 & 8 & 9 & 10 & 10 \\
\hline 5 & 8 & 9 & 11 & 14 & 12 & 14 \\
\hline 6 & 6 & 8 & 9 & 11 & 11 & 13 \\
\hline 7 & 9 & 8 & 14 & 16 & 15 & 16 \\
\hline \multicolumn{7}{|c|}{ Subgroup III } \\
\hline 1 & 13 & 14 & 16 & 16 & 15 & 14 \\
\hline 2 & 12 & - & 16 & - & 17 & - \\
\hline 3 & 14 & 11 & 18 & 17 & 19 & 19 \\
\hline 4 & 12 & 11 & 13 & 12 & 13 & 13 \\
\hline 5 & 12 & 13 & 14 & 15 & 14 & 15 \\
\hline 6 & 11 & 11 & 13 & 12 & 14 & 14 \\
\hline
\end{tabular}


Table 5

Results of Schirmer tear test I

\begin{tabular}{|c|c|c|c|c|c|c|}
\hline & \multicolumn{6}{|c|}{$\begin{array}{l}\text { Result of Schirmer tear test I (mm) } \\
\text { Median (minimum-maximum values) }\end{array}$} \\
\hline & \multicolumn{2}{|c|}{ Before treatment } & \multicolumn{2}{|c|}{ After 1 month of treatment } & \multicolumn{2}{|c|}{ After 2 months of treatment } \\
\hline & Right eye & Left eye & Right eye & Left eye & Right eye & Left eye \\
\hline Group I & $\begin{array}{c}8.5 \\
(2-14)\end{array}$ & $\begin{array}{c}9.0 \\
(0-13)\end{array}$ & $\begin{array}{l}11.0 \\
(4-17)\end{array}$ & $\begin{array}{l}11.0 \\
(0-17)\end{array}$ & $\begin{array}{l}13.0^{*} \\
(2-19)\end{array}$ & $\begin{array}{l}12.5^{*} \\
(0-20)\end{array}$ \\
\hline Group II & $\begin{array}{c}8.0 \\
(0-14)\end{array}$ & $\begin{array}{c}8.0 \\
(2-14)\end{array}$ & $\begin{array}{l}12.5^{* *} \\
(1-18)\end{array}$ & $\begin{array}{l}12.0^{* *} \\
(1-17)\end{array}$ & $\begin{array}{l}13.0^{* *} \\
(1-19)\end{array}$ & $\begin{array}{l}14.0^{* *} \\
(0-19)\end{array}$ \\
\hline
\end{tabular}

Statistically significant differences: ${ }^{*} \mathrm{P}<0.05 ;{ }^{* *} \mathrm{P}<0.01$

Table 6

Assessment of vascular ingrowth and corneal pigmentation in Group I

\begin{tabular}{|c|c|c|c|c|c|c|}
\hline & \multicolumn{2}{|c|}{ Before treatment } & \multicolumn{2}{|c|}{$\begin{array}{l}\text { After } 1 \text { month } \\
\text { of treatment }\end{array}$} & \multicolumn{2}{|c|}{$\begin{array}{c}\text { After } 2 \text { months } \\
\text { of treatment }\end{array}$} \\
\hline & Right eye & Left eye & Right eye & Left eye & Right eye & Left eye \\
\hline $\begin{array}{l}\text { Number of corneal quad- } \\
\text { rants affected by neovas- } \\
\text { cularisation }\end{array}$ & 38 & 44 & $28^{*}$ & $27^{* * *}$ & $19^{*}$ & $16^{* * *}$ \\
\hline $\begin{array}{l}\text { Degree of corneal pig- } \\
\text { mentation }\end{array}$ & 26 & 24 & 22 & 20 & 19 & 16 \\
\hline
\end{tabular}

Statistically significant differences: ${ }^{*} \mathrm{P}<0.05 ;{ }^{* * *} \mathrm{P}<0.001$

Table 7

Assessment of vascular ingrowth and corneal pigmentation in Group II

\begin{tabular}{|c|c|c|c|c|c|c|}
\hline & \multicolumn{2}{|c|}{ Before treatment } & \multicolumn{2}{|c|}{$\begin{array}{l}\text { After } 1 \text { month } \\
\text { of treatment }\end{array}$} & \multicolumn{2}{|c|}{$\begin{array}{l}\text { After } 2 \text { months } \\
\text { of treatment }\end{array}$} \\
\hline & Right eye & Left eye & Right eye & Left eye & Right eye & Left eye \\
\hline $\begin{array}{l}\text { Number of corneal quad- } \\
\text { rants affected by neovas- } \\
\text { cularisation }\end{array}$ & 51 & 34 & $24^{* * *}$ & $24^{*}$ & $12^{* * *}$ & $14^{*}$ \\
\hline $\begin{array}{l}\text { Degree of corneal pig- } \\
\text { mentation }\end{array}$ & 22 & 21 & 21 & 18 & 14 & 15 \\
\hline
\end{tabular}

Statistically significant differences: ${ }^{*} \mathrm{P}<0.05 ;{ }^{* * *} \mathrm{P}<0.001$ 

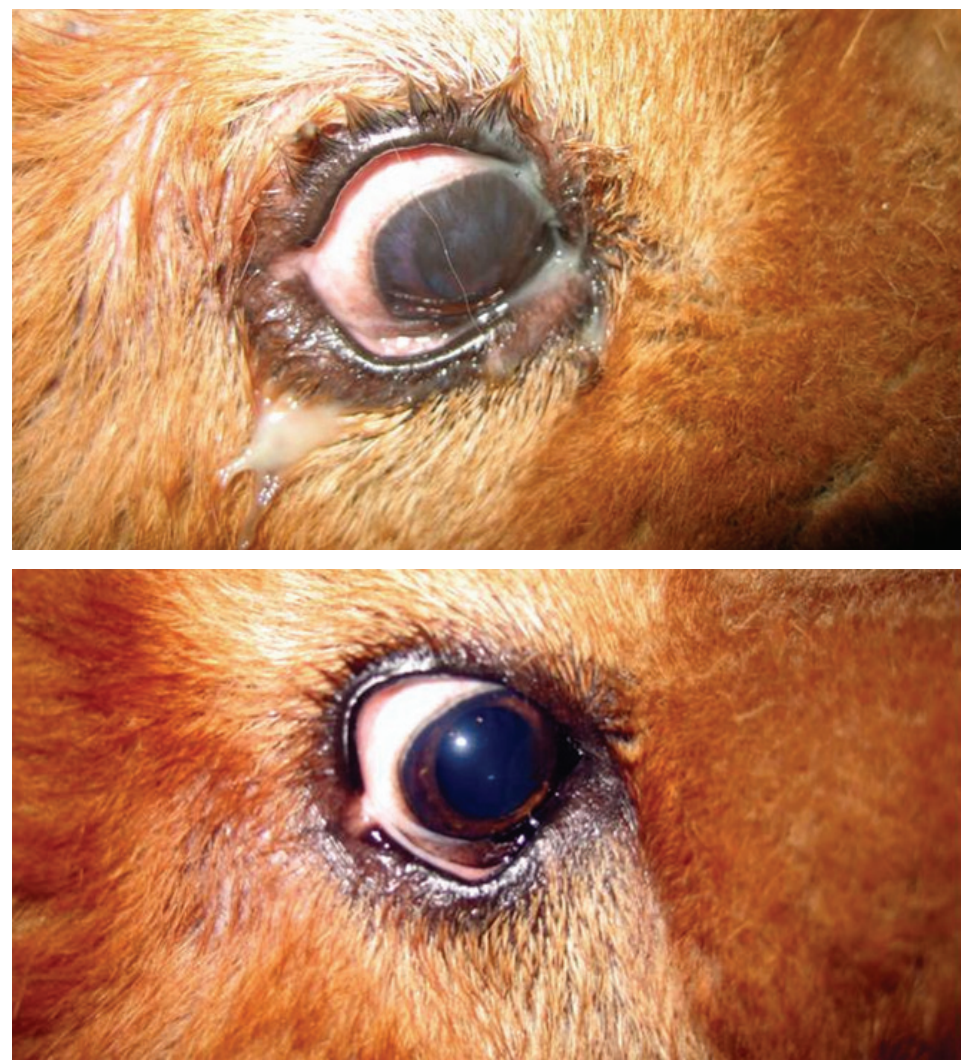

Fig. 1. Right eye of a 6 years old male Chow Chow (patient no. 6 from Subgroup I of Group I) treated with cyclosporine. Top: At presentation. Schirmer tear test $(\mathrm{STT})=5$, conjunctival hyperaemia - score 2 , ocular discharge - score 4 , corneal pigmentation - score 4 , corneal transparency - score 1, corneal neovascularisation - score 4, corneal defect - score 0 .

Bottom: After 8 weeks of treatment. Schirmer tear test $(\mathrm{STT})=12$, conjunctival hyperaemia score 1 , ocular discharge - score 2, corneal pigmentation - score 1, corneal transparency - score 0 , corneal neovascularisation - score 1 , corneal defect - score 0

In both groups, some patients were observed to exhibit inhibited development of pigmentation but an analysis of particular clinical cases and statistical data revealed no statistically significant discrepancies in the course of the study (Tables 6 and 7). Treatment with both tacrolimus and cyclosporine led to a reduction of pigmentation in certain, most advanced cases (Fig. 1). In subgroup I of Group I, out of 9 corneas affected by pigmentation during the course of the study, improvement was observed in 4 cases; by comparison, in Group II, improvement was also observed in 4 corneas, although the total number of corneas affected by pigmentation prior to the study was 10 . In one patient treated with tacrolimus, after the first month, the degree of pigmentation decreased but then returned to the pre-treatment state after two months of therapy. 

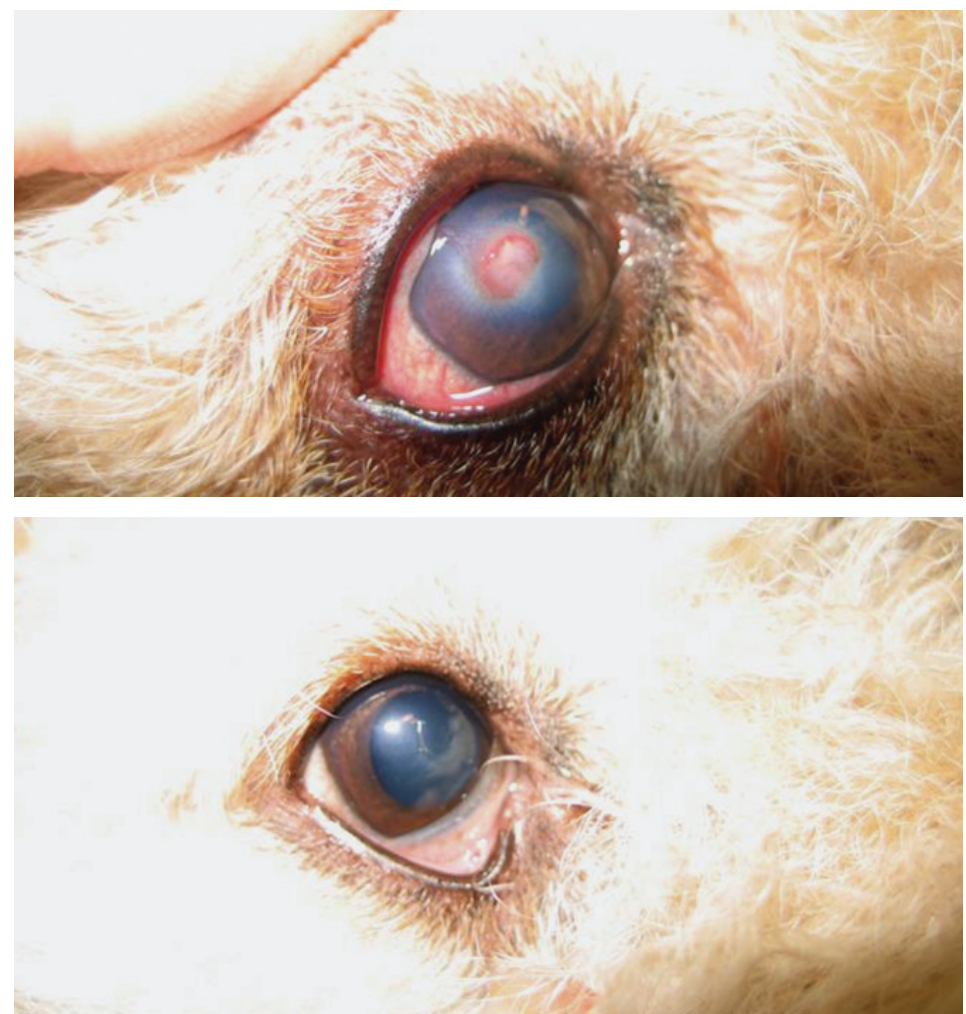

Fig. 2. Right eye of a 12 years old male Poodle (patient no. 7 from Subgroup II of Group II) treated with tacrolimus. Top: At presentation. Schirmer tear test $(\mathrm{STT})=9$, conjunctival hyperaemia score 3, ocular discharge - score 3, corneal pigmentation - score 0 , corneal transparency - score 1 , corneal neovascularisation - score 4, corneal defect - score 1. Bottom: After 8 weeks of treatment.

Schirmer tear test $(\mathrm{STT})=15$, conjunctival hyperaemia - score 1 , ocular discharge - score 2 , corneal pigmentation - score 0 , corneal transparency - score 0 , corneal neovascularisation - score 0 , corneal defect - score 0

The administered treatment led to adequate healing of corneal ulceration within the first month of therapy (Fig. 2), the only exceptions being defects in one patient in subgroup I of Group I, and one patient in subgroup II of Group I, where healing was observed after two months.

\section{Discussion}

Keratoconjunctivitis sicca is an eye disease which may lead to significant eyesight impairment. Despite the high efficacy of cyclosporine in KCS treatment some patients can be resistant to its effects, which is why research is continuously under way with the aim of finding alternative treatment methods (Cham- 
bers et al., 2002). Few publications are available on the use of tacrolimus in the treatment of KCS. To date, there has been no in-depth comparative research into the efficacy of tacrolimus and cyclosporine in the treatment of immunological KCS. In the present study, $0.02 \%$ tacrolimus was administered twice daily and its efficacy was compared to $0.75 \%$ cyclosporine administered in the standard dosage, three times a day. The concentration and frequency of tacrolimus administration were in line with the results obtained by Berdoulay et al. (2005).

Cyclosporine significantly reduces exudation and conjunctival hyperaemia (Sansom et al., 1995). In the present study, a gradual decrease of exudation and conjunctival redness was observed in the course of both treatments. However, based on the specific results pertaining to eliminating exudation, tacrolimus can be reported to show greater effectiveness than cyclosporine. In dogs treated with tacrolimus, the amount of exudate was reduced in $100 \%$ of the patients after the 2-month therapy, whereas in the group treated with cyclosporine the amount of exudate present in 3 conjunctival sacs persisted at the same level throughout the treatment. It is also important to notice that high efficacy of the tested preparations was also demonstrated in patients with advanced clinical symptoms of the disease. In an earlier study by Berdoulay et al. (2005), the researchers reported a significant reduction of exudation and reduced conjunctival redness after administering tacrolimus. Moreover, the authors observed improvement in terms of these symptoms also in a group of patients previously unsuccessfully treated with cyclosporine.

Numerous studies indicate that cyclosporine is highly effective in treating canine KCS. It alleviates the clinical symptoms and improves the STT results (Kaswan et al., 1989; Morgan and Abrams, 1991; Olivero et al., 1991; Herrera and Lightowler, 1994). As the quoted authors used cyclosporine in various concentrations, in the form of either ointment or drops, the reported STT improvement varied accordingly. Kaswan et al. (1989) administered 2\% cyclosporine in the treatment of KCS and reported an increase in STT values of $5 \mathrm{~mm}$ or more in $59 \%$ of the patients. In another study, Morgan and Abrams (1991) reported an increase of STT results in $60 \%$ of patients with initial STT values within the range from 0 to $2 \mathrm{~mm}$, and in $90-92 \%$ in dogs with an initial STT of over $3 \mathrm{~mm} /$ min. Furthermore, the authors observed a significant regression of clinical symptoms, which brought considerable relief to the patients and improved their eyesight. Cyclosporine was also successfully used in different concentrations. Herrera and Lightowler (1996) used 0.2\% ophthalmic ointment in the treatment of KCS and reported an average STT improvement of $10 \mathrm{~mm} / \mathrm{min}$ after a 28-day therapy. In yet another study, the authors administered eye drops containing $1 \%$ cyclosporine and reported an increase in STT results of $5 \mathrm{~mm} / \mathrm{min}$ or more in $86 \%$ of the cases (Olivero et al., 1991). In the present study, an increase in STT results was observed both for cyclosporine and tacrolimus. Similarly, in the research by Hendrix et al. (2011), increased STT values were reported in both a 
group of dogs receiving $0.03 \%$ tacrolimus eye drops and a group receiving $2 \%$ cyclosporine, without statistically significant discrepancies between the two. A greater increase in STT values was observed after administering $1 \%$ pimecrolimus when compared to $0.2 \%$ cyclosporine (Ofri et al., 2009). In a short-term study conducted by Berdoulay et al. (2005) it was reported that in patients suffering from KCS and successfully treated with cyclosporine, it was possible to replace the preparation with tacrolimus and maintain the same results. Furthermore, the authors observed $51 \%$ efficacy of tacrolimus in patients either entirely unresponsive to cyclosporine or showing only very weak response to the drug. In the present study, tacrolimus was also observed to be more effective than cyclosporine, confirming the results obtained by Berdoulay et al. (2005). In the course of a two-month therapy, an increase in STT I results of $5 \mathrm{~mm} / \mathrm{min}$ or more was observed in 21 out of 37 conjunctival sacs in the group of dogs treated with tacrolimus, compared to 15 out of 38 conjunctival sacs in the group treated with cyclosporine. It should be emphasised that both in the case of tacrolimus and cyclosporine, certain cases were recorded where STT results decreased. The same may be attributed to the progressing atrophy of lacrimal glands and the related lack of responsiveness to tear production stimulants.

It is believed that KCS in Yorkshire Terriers may be congenital. However, immune-mediated KCS can affect this breed as much as any other dog. Lacrimal gland aplasia or hypoplasia should be considered in young dogs with severe unilateral ocular dryness (Herrera et al., 2007; Westermeyer et al., 2009). In the present study, unilateral KCS was diagnosed in one dog aged 4 years and in two younger animals aged 1 and 1.5 years, respectively. It is believed that when congenital alacrima is suspected, cyclosporine treatment should be administered as it tends to yield a better prognosis (Westermeyer et al., 2009). In the present study the cyclosporine treatment yielded no improvement in two Yorkshire Terrier dogs from Group I (a one-year-old male with unilateral KCS and a 12-year-old female with bilateral KCS), while in three other animals, an increase in STT I values and regression of clinical symptoms were observed. In Group II, in all dogs treated with tacrolimus, an increase in STT I values and regression of clinical symptoms were observed. It can be assumed that the one-year-old Yorkshire Terrier patient from Group I (patient no. 5 from subgroup I showing no signs of improvement after the administration of cyclosporine treatment) may have suffered from congenital alacrima.

Earlier studies demonstrated high efficacy of cyclosporine in inhibiting vascular ingrowth in patients suffering from KCS (Olivero et al., 1991). However, the available literature does not provide information on the efficacy of tacrolimus with regard to limiting corneal neovascularisation in KCS patients. In the present study, inhibition of vascular ingrowth was observed in both study groups, although in the case of advanced and intermediate disease stages the efficacy of tacrolimus in this respect was demonstrably higher when compared to cyc- 
losporine. The same was evidenced by a greater number of corneal quadrants and corneas where neovascularisation was observed to have been reduced as a result of the therapy. Regression of corneal neovascularisation is an important element of KCS treatment, as by reducing the number of ingrown blood vessels, corneal transparency is improved and pigmentation reduced, which significantly improves the patients' eyesight.

Reduction of pigmentation is among the most challenging aspects of treating chronic keratitis. Morgan and Abrams (1991) observed a 67\% reduction of pigmentation when using cyclosporine treatment. Corneal pigmentation was also reduced in a several months long KCS treatment with cyclosporine (Olivero et al., 1991). The present study does not confirm the alleged high efficacy of cyclosporine in eliminating corneal pigmentation in dogs suffering from KCS. In several patients the development of pigmentation was inhibited but pigmentation as such was not reduced, as evidenced by an analysis of individual clinical cases and statistical data. The available literature does not mention the efficacy of tacrolimus with regard to limiting pigmentation in KCS patients. Berdoulay et al. (2005) only mention that an improvement in terms of pigmentation and neovascularisation was reported by the owners within 10-14 days of initiating the treatment. In the present study, no cases were observed where further progression of pigmentation would occur despite the treatment, either in the tacrolimus or in the cyclosporine groups. The only exception was one patient treated with tacrolimus, where after the first month the degree of pigmentation was decreased but returned to the pre-treatment state after the second month of therapy. The lack of significant improvement in terms of pigmentation may also result from the stage of advancement of the clinical symptoms. The same is suggested by the results obtained in the present study, where some patients diagnosed with subclinical KCS showed a reduction in the extent of pigmentation when treated with either tacrolimus or cyclosporine. In more advanced stages, where corneal pigmentation was more common, with the exception of certain isolated cases the degree of pigmentation remained unchanged throughout the treatment. Therefore, the obtained results indicate that the use of both tacrolimus and cyclosporine may inhibit further development of pigmentation in KCS patients but rarely causes reduction of the same.

In the present study, in all dogs treated with cyclosporine the corneal defects healed during the two-month treatment. Earlier studies by Sansom et al. (1995) also reported healing of corneal ulcerations in cases of canine KCS. Out of 41 damaged corneas, 26 healed in the course of a 42-day therapy. In the present study, all observed corneal defects healed already in the first month of treatment but the mechanism of healing corneal ulcerations in KCS cases treated with tacrolimus requires further research.

The present research revealed no side effects, neither systemic nor local, resulting from receiving $0.02 \%$ tacrolimus eye drops. Cases of irritation caused 
by cyclosporine have been reported in the literature (Sansom et al., 1995). Izci et al. (2002) mentioned irritative effects of the preparation in some patients, which tended to subside within the first 10 days of treatment as the clinical symptoms of the disease were alleviated. In the present study, 4 patients were reported to have suffered mild irritation in response to the medicine, as evidenced by the attempts to rub the vicinity of the eye socket. Such side effects were not observed for tacrolimus. The mentioned irritative effects of cyclosporine eye drops were short lasting (not longer than several minutes after administration), and did not influence the course of the study. Moreover, in most patients the tendency to rub of the orbital region would eventually cease or become less intensive within 2-3 weeks from the beginning of the treatment.

To recapitulate the obtained results, it should be concluded that tacrolimus may be used in the treatment of all clinical stages of canine KCS. In advanced stages of canine KCS tacrolimus may indeed prove more effective than cyclosporine.

\section{References}

Aguirre, G., Rubin, L. and Harvey, C. (1971): Keratoconjunctivitis sicca in dogs. J. Am. Vet. Med. Ass. 158, 1566-1579.

Balicki, I., Radziejewski, K. and Silmanowicz, P. (2008): Studies on keratoconjunctivitis sicca incidence in crossbred dogs. Pol. J. Vet. Sci. 11, 353-358.

Bartnett, K. (1997): Diagnosis and treatment of keratoconjunctivitis sicca in the dog. Vet. Rec. 120, 340-345.

Berdoulay, A., English, R. and Nadelstein, B. (2005): Effect of topical 0.02\% tacrolimus aqueous suspension on tear production in dogs with keratoconjunctivitis sicca. Vet. Ophthalmol. 8, $225-232$.

Bonagura, J. D. and Twedt, D. C. (2009): Kirk's Current Veterinary Therapy XIV. Saunders Elsevier, St. Louis, Missouri, USA.

Chambers, L., Fischer, C., McCalla, T., Parshall, C., Slatter, D. and Yakley, B. (2002): Topical tacrolimus in treatment of canine keratoconjunctivitis sicca: a multicenter preliminary clinical trial. Materials of Scientific Meeting of the American College of Veterinary Ophthalmologists, Denver.

Gilger, B. C., Wilkie, D. A., Salmon, J. H. and Peel, M. R. (2013): A topical aqueous calcineurin inhibitor for the treatment of naturally occurring keratoconjunctivitis sicca in dogs. Vet. Ophthalmol. 16, 192-197.

Giuliano, E. A. and Moore, C. P. (2007): Diseases and surgery of the lacrimal secretory system. In: Gelatt, K. N. (ed.) Veterinary Ophthalmology. 4th edition. Blackwell Publishing, Ames. pp. 633-661.

Hendrix, D. V., Adkins, E. A., Ward, D. A., Stuffle, J. and Skorobohach, B. (2011): An investigation comparing the efficacy of topical ocular application of tacrolimus and cyclosporine in dogs. Vet. Med. Int. 2011; 2011: 487592. doi: 10.4061/2011/487592.

Herrera, H. D. and Lightowler, C. H. (1994): Retrospective study: Use of the cyclosporine A on canine KCS in Argentina (1991-1993). Materials of the Annual Meeting of the ECVO, Dresden, Germany.

Herrera, H. D. and Lightowler, C. H. (1996): Lacrimomimetic effect of the cyclosporine A $(0.2 \%$ ophthalmic ointment) on the canine keratoconjunctivitis sicca. IV Encuentro Latinoamericano de Oftalmologa Veterinaria, Ribeirao Preto, Brazil. 
Herrera, H. D., Weichsler, N., Gómez, J. R. and de Jalón, J. A. (2007): Severe, unilateral, unresponsive keratoconjunctivitis sicca in 16 juvenile Yorkshire Terriers. Vet. Ophthalmol. 10, 285-288.

Izci, C., Celik, I., Alkan, F., Ogurtan, Z., Ceylan, C., Sur, E. and Ozkan, Y. (2002): Histologic characteristics and local cellular immunity of the gland of the third eyelid after topical ophthalmic administration of $2 \%$ cyclosporine for treatment of dogs with keratoconjunctivitis sicca. Am. J. Vet. Res. 63, 688-694.

Kaswan, R. L., Bounous, D. and Hirsh, S. (1995): Diagnosis and management of keratoconjunctivitis sicca. Vet. Med. 90, 539-560.

Kaswan, R. L., Martin, C. L. and Chapman, W. L. (1984): Keratoconjunctivitis sicca: histopathologic study of nictitating membrane and lacrimal glands from 28 canine cases. Am. J. Vet. Res. 45, 112-118.

Kaswan, R. L., Martin, C. and Dawe, D. (1985): Keratoconjunctivitis sicca: immunological evaluation of 62 canine cases. Am. J. Vet. Res. 46, 376-383.

Kaswan, R. L., Salisbury, M. A. and Ward, D. (1989): Spontaneous canine keratoconjunctivitis sicca. A useful model for human keratoconjunctivitis sicca: treatment with cyclosporine eye drops. Arch. Ophthalmol. 107, 1210-1216.

Kilmartin, D. J., Forrester, J. V. and Dick, A. D. (1998): Tacrolimus (FK506) in failed cyclosporin A therapy in endogenous posterior uveitis. Ocul. Immunol. Inflamm. 6, 101-109.

Kino, T., Hatanaka, H., Hashimoto, M., Nishiyama, M., Goto, T., Okuhara, M., Kohsaka, M., Aoki, H. and Imanaka, H. (1987): FK 506, a novel immunosuppressant isolated from a Streptomyces. I. Fermentation, isolation, and physico-chemical and biological characteristics. J. Antibiot. 40, 1249-1255.

Miller, P. E. (2008): Lacrimal system. In: Maggs, D. J., Miller, P. E. and Ofri, R. (eds) Slatter's Fundamentals of Veterinary Ophthalmology. 4th edition. Saunders Elsevier, St. Louis, Missouri, USA. pp. 157-174.

Morgan, R. V. and Abrams, K. L. (1991): Topical administration of cyclosporine for treatment of keratoconjunctivitis sicca in dogs. J. Am. Vet. Med. Ass. 199, 1043-1046.

Ofri, R., Lambrou, G. N., Allgoewer, I., Graenitz, U., Pena, T. M., Spiess, B. M. and Latour, E. (2009): Clinical evaluation of pimecrolimus eye drops for treatment of canine keratoconjunctivitis sicca: a comparison with cyclosporine A. Vet. J. 179, 70-77.

Olivero, D. K., Davidson, M. G., English, R. V., Nasisse, M. P., Jamieson, V. E. and Gerig, T. M. (1991): Clinical evaluation of $1 \%$ cyclosporine for topical treatment of keratoconjunctivitis sicca in dogs. J. Am. Vet. Med. Ass. 199, 1039-1042.

Sansom, J., Barnett, K. C., Neumann, W., Schulte-Neumann, A., Clerc, B., Jegou, J. P., de Haas, V. and Weingarten, A. (1995): Treatment of keratoconjunctivitis sicca in dogs with cyclosporine ophthalmic ointment: a European clinical field trial. Vet. Rec. 137, 504-507.

Trbolova, A. (2005): Diagnosis and therapy of keratoconjunctivitis sicca in dogs [in Slovak]. Infovet. 6, 250-252.

Westermeyer, H. D., Ward, D. A. and Abrams, K. (2009): Breed predisposition to congenital alacrima in dogs. Vet. Ophthalmol. 12, 1-5.

Whitley, D., McLaughlin, S., Gilger, B. and Lindley, D. (1991): The treatments for keratoconjunctivitis sicca. Vet. Med. 11, 1076-1093. 